\title{
LITERATURA INDÍGENA NA ESCOLA: A TEORIA A FAVOR DA PRÁTICA NO ENSINO
}

\section{INDIGENOUS LITERATURE IN SCHOOL: THEORY IN FAVOR OF PRACTICE IN TEACHING}

\author{
Leila Silvia Sampaio ${ }^{1}$ \\ Rosana Rodrigues da Silva ${ }^{2}$
}

Recebido em: 21 jan. 2019

Aceito em: 10 abr. 2019

DOI 10.26512/aguaviva.v4i2.23842

RESUMO: Este trabalho objetiva discutir o ensino da literatura indígena, partindo do aporte teórico e metodológico que vem se abrindo para o conhecimento a favor da prática no ensino. A pesquisa bibliográfica revela que, atualmente, tem-se a preocupação com a discussão do tema que vem se expandido nos centros acadêmicos. As pesquisadoras Janice Thiél (2012), Graça Graúna (2013), Sueli de Souza Cagnetti e Alcione Pauli (2015) apresentam estudos acerca da literatura indígena, propostas de formação profissional e prática em sala de aula, com o intuito de levar conhecimento acerca do contexto da produção de literatura indígena para que a prática se efetiva ao encontro do objetivo literário, formar leitores mais críticos e aproximar as diferenças com a promoção do respeito. A fim de exemplificar possibilidades de estudo, o artigo apresenta a obra As fabulosas fábulas de Iauraetê (2007) do autor Kaká Werá Jecupé que compõe excelente material de auxílio no ensino e aprendizagem dessa literatura. Adquirir conhecimento a respeito da literatura indígena é relevante para que as práticas de ensino com as obras literárias dessa autoria sejam exploradas de maneira que favoreça seus objetivos.

Palavras-chave: Literatura indígena; Teoria; Ensino.

ABSTRACT: The objective of this work is to discuss the teaching of indigenous literature, starting from the theoretical and methodological contribution that has been opening up to the knowledge in favor of practice in teaching. The bibliographical research reveals that, at present, it has the preoccupation with the discussion of the subject that has been expanded in the

\footnotetext{
${ }^{1}$ Mestranda no PPGLetras da Universidade do Estado de Mato Grosso (UNEMAT), no campus de Sinop. Possui graduação em Letras-Português/Inglês pela Universidade Estadual de Maringá. Pós-graduação em Psicopedagogia pela Faculdade de Selviria. Docente das disciplinas de Língua Portuguesa e Inglesa na Escola Estadual Professora Alzira Maria da Silva desde 2000 e diretora nos anos de 2012 a 2015 na mesma instituição. Atualmente, está em regência como professora de Língua Portuguesa para o ensino fundamental. E-mail: leilasilvia70@ hotmail.com

${ }^{2}$ Doutora em Letras pela Universidade Estadual Paulista (UNESP) de São José do Rio Preto. Mestre em Letras pela Universidade Federal do Rio Grande do Sul (UFRGS) e graduada em Letras pela UNESP, campus de Assis. Professora efetiva do curso de graduação em Letras, do Mestrado profissionalizante (PROFLETRAS) e do mestrado acadêmico (PPGLetras), da Universidade do Estado do Mato Grosso (UNEMAT), campus de Sinop. Integra o grupo Estudos comparativos de Literatura: tendências identitárias, diálogos regionais e vias discursivas. É editora do periódico do curso de Letras da UNEMAT, de Sinop, Revista de Letras Norte@mentos (ISSN 19838018), desde 2008. E-mail: rosana.silva@unemat.br
} 
academic centers. Researchers Janice Thiél (2012), Graça Graúna (2013), Sueli de Souza Cagnetti and Alcione Pauli (2015) present studies about indigenous literature. They propose professional and practical training in the classroom, with the aim of bringing knowledge about the context of the production of indigenous literature, so that the practice becomes effective to meet the literary objective, which is to train more critical readers and to bring the differences closer together with the promotion of respect. In order to exemplify possibilities of study, the article presents the book As fabulosas fábulas de Iauraetê (2007) by the author Kaká Werá Jecupé that composes excellent aid material in the teaching and learning of this literature. Acquiring knowledge about indigenous literature is relevant so that the teaching practice with the literary works of this author gets explored in a way that favors its objectives.

Keywords: Indigenous literature; Theory; Teaching.

\section{INTRODUÇÃO}

Pesquisas em torno da literatura indígena demonstram a importância do embasamento teórico e metodológico aos professores para que os textos escritos pelos índios possam ser trabalhados em sala de aula com conhecimento de sua contextualização cultural e estética. Entende-se que a formação do professor precisa ampará-lo para abordar uma parte da história que envolve questões relacionadas ao processo de colonização do Brasil, o qual nos foi contado pelo olhar do colonizador, enraizando conhecimentos equivocados que desencadearam conceitos, hoje, questionáveis nas escolas.

Em função da Lei 11.645/08, que obriga estudos de temáticas indígenas e africanas, o governo busca levar material teórico às escolas que contemplem a formação profissional. No entanto, preocupa o pouco conhecimento acerca de como trabalhar esses textos de literatura indígena que podem auxiliar em trabalhos interventivos que oportunizam conhecimento e desconstruções de conceitos errôneos enraizados pelo tempo. Diante disso, este trabalho objetiva trazer considerações acerca da literatura indígena, seu ensino, abordando a questão do apoio teórico que pesquisadores como Janice Thiel (2012), Graça Graúna (2013), Sueli de Souza Cagnetti e Alcione Pauli (2015) colaboram para que essa produção seja entendida em sua forma artística e literária e de auxílio à formação de um leitor mais crítico.

Os estudos que as pesquisadoras desenvolveram permitem encontrar um caminho de conhecimento das produções de autoria indígena que podem auxiliar o professor a entender a respeito dessa produção e sugestões de práticas de como podem se dar os estudos acerca dessa literatura em sala de aula. Para elucidar, será apresentada a obra As fabulosas fábulas de 
Iauaretê (2007) do escritor Kaká Werá Jecupé pela sua composição significativa e de conceituação de produção literária indígena proposta para um possível trabalho em sala.

\section{Da oralidade à escrita: a literatura indígena em foco.}

De acordo com Thiél (2012, p. 11), "Literatura é a arte da palavra e a palavra diz o mundo, diz os seres que nele habitam e diz sua história, suas relações, encontros, conflitos, buscas e questionamentos". Esse conceito abrange a produção literária indígena que, embora esteja em ascensão há mais de vinte anos, recebe olhares interrogativos nas instituições de ensino. Esse quadro vem apresentando uma mudança significativa pelo número considerável de autores e pesquisadores que cresce e ajuda na propagação dessa literatura e seus objetivos: entreter, levar conhecimento, promover o respeito e valorização de sua história, assim como o fortalecimento de sua identidade e cultura.

Considerada um instrumento de resistência, a literatura indígena soma-se às lutas que começam em meados da década de 70 , período que marca o surgimento de movimentos e organizações em defesa dos direitos e interesse desses povos. A reação ao poder que se expandia com as demarcações de terras pelos interesses de minerados, madeireiros, construtores de rodovias e hidroelétricas se expressa em "manifestações identitárias que se expandem como fonte de resistência contra as decepções acumuladas ao longo dos 500 anos" (GRAÚNA, 2013, p. 38). Nesse sentido, a literatura indígena, pelo seu caráter político-cultural é defendida como:

um meio para uma práxis político-pedagógica de resistência, de luta e de formação em que as diferenças assumem protagonismo central e escrevem outras histórias do Brasil, seu passado e seu presente, nos convidando a pensar o país a partir de sua condição como minorias, como diferenças. Por outras palavras, além de um fenômeno estético-literário singular, merecedor de avaliação e de publicização, além de sua estrutura paradigmática alternativa às formas paradigmáticas calcadas na racionalização, a literatura indígena é também práxis político-pedagógica de resistência e de luta, marcada pelo ativismo, pela militância e pelo engajamento das próprias vítimas de nossa modernização conservadora (DORRICO et al. 2018, p. 12).

Por séculos tivemos o índio sendo excluído de seu verdadeiro perfil, inserido em discursos que o reduzia, que o calava e, segundo Thiél (2012), uma visão estereotipada em função da construção identitária do índio no contato com o europeu desde o período colonial, colabora para que o indígena faça parte de um imaginário que não traduz sua verdadeira essência. Diante disso, para compreender a produção indígena brasileira, a pesquisadora 
defende que "é importante que se conheça o que o outro escreveu sobre ele. [...] porque esses textos que ainda hoje pautam o imaginário ocidental interferem na leitura do índio.”

Registros do período colonial pela perspectiva do olhar europeu, contribuiram para que os conceitos se enraizassem e de acordo com Thiél (2012, p. 62):

Caminha, Gândavo e Léry imprimem no imaginário ocidental uma série de construções que marcam por séculos, a caracterização do índio. Como narradores colonialistas, eles escrevem sobre o outro a partir de uma posição eurocêntrica; na maior das vezes, seu posicionamento ideológico desqualifica a sociedade nativa diante da europeia.

A literatura brasileira desse período teve sua contribuição ao representar o índio "como hóspede em sua própria terra; cordial quando submisso; hostil quando rebelde; esquivo e inconstante; carente de lei, rei e fé; inocente, mas cruel. (THIÉL, 20112, p. 62)

A representação do índio na literatura ocidental provoca o indígena a retomar sua voz, e se apropriar da escrita. Segundo Dorrico (2018, p. 230)

Essas novas vozes têm a função de enunciar suas pertenças ancestrais de modo criativo e, nessa esteira, descontruir noções sedimentadas que se conservam no imaginário popular sobre elas, marcadas por um viés fortemente negativo e preconceituoso.

Desse ponto, nasce a literatura indígena brasileira das comunidades consideradas periféricas, como forma de afirmação cultural e identitária. A respeito disso, o escritor indígena Jekupé (2018, p. 46) contribui:

faz tantos séculos que o Brasil foi dominado pelos jurua kuery, não Índios em guarani, e desde aquela época tudo o que se fala sobre nossos parentes é escrito por eles. Eu não via isso como algo interessante, porque nós temos que contar nossas histórias para nossos filhos e se tiver que ser escrita, por que não pelo próprio índio?

Tecida pelo sentimento de exclusão e pela busca do reconhecimento e valorização negados no passado, a literatura indígena surge ocupando espaços, ressignificando conceitos. A autoria, nesse contexto, fomenta discussões acerca das produções literárias indígenas, instrumentos para estudos em sala que fortalecem o que os autores buscam em suas produções: levar conhecimento a respeito das culturas indígenas brasileiras, firmarem suas identidades e promover o respeito. 


\section{Literatura Indígena na escola: teoria e prática}

Os textos de literatura indígena nas unidades escolares parecem passar despercebidos pelos profissionais. Muitos alegam não ter conhecimento da presença dessas produções na escola, embora o livro esteja na estante da biblioteca. Outros afirmam saber da existência dessa literatura, mas parecem desconsiderar a riqueza que existe dentro dos livros de autoria indígena e assim, não intencionalmente, ignoram um conhecimento que pode contribuir para um trabalho de estudos e práticas com professores e alunos.

A Secretaria de Educação do Estado de Mato Grosso tem disponibilizado às escolas materiais teóricos que abordam a diversidade cultural, a história da nossa cultura oriunda dos nativos e dos negros escravizados, como também obras de literatura de autores indígenas como Daniel Mundurku, Olìvio Jekupé, René Kithãulu, Yaguarê Yamã, entre outros. Dessa maneira, é possível encontrar acervo nas escolas que abordam a história dos índios e negros e obras literárias que favorecem o trabalho em sala.

Os estudos em torno dessas temáticas são necessários, não somente para atender à Lei 11.645/08, mas para que tenhamos a formação do leitor multicultural, que leia o mundo e suas diferenças com olhar mais crítico e de respeito. Nesse sentido, são importantes o conhecimento e a compreensão por parte dos profissionais da educação, a fim de que o trabalho alcance os objetivos propostos pela teoria que muitos estudiosos, pesquisadores e autores indígenas apontam.

Entende-se que o assunto, por vezes, preocupa os profissionais que precisam se aprofundar na história, buscar mais conhecimento a respeito de uma construção historicamente imposta e que se enraizou de forma que, hoje, traz dúvidas e muitos questionamentos, tornando o assunto um "campo minado" para os educadores que terão que revisar seus próprios conceitos.

De acordo com Thiél (2012), os textos indígenas são calcados nos próprios valores e visões do universo cultural indígena e buscam demarcar novas identidades étnicas. Além da preocupação em tratar a "questão da inclusão social e cultural", e a revisão de uma história, deve-se se atentar à construção de repertório dos alunos e o desenvolvimento da criticidade. Nesse caso, a literatura promove o debate de temáticas e as formas como são abordadas. Para essa mediação na formação educacional do aluno, Thiél (2012, p. 11-12) colabora: 
Compreendemos que, como mediadores de leituras, os professores exercem um papel essencial na formação de leitores competentes. A leitura de obras literárias, em especial, promove percepção não só de temas variados, mas de como esses temas são abordados [...] se restringimos nossas leituras a certos grupos e visões, limitamos também nosso aprendizado e nossa possibilidade de ver e ler o mundo de uma maneira dinâmica. Portanto, é fundamental que formemos leitores que possam criar conexões entre saberes, perceber o lugar ideológico dos discursos, interpretar informações e desenvolver consciências.

Assim, os alunos devem entender o lugar ideológico do discurso indígena, para que se sintam capacitados a interpretar informações e desenvolver a leitura crítica que busca formar, embasa a necessidade do profissional se preparar, conhecer a respeito da autoria indígena, saber dos seus objetivos e oportunizar que sejam alcançados.

\section{A contribuição dos estudos de Thiél (2012), Graúna (2013), Cagnetti e Pauli (2015): teorias e propostas para o ensino.}

A literatura indígena abre caminho para que estudos acerca de sua produção venham esclarecer assuntos relacionados à história dos índios na construção do nosso país, sua representação na literatura brasileira, o caráter literário dessa produção, suas especificidades e a autoria na esfera cultural e política, assim como propostas de ensino com seus textos. Entre tantos, este trabalho apresenta três obras que trazem discussões em torno da produção que podem ajudar o profissional a embasar sua prática de ensino e propostas que exemplificam possíveis trabalhos com os alunos na intenção de explorar os textos de literatura indígena em sala de aula.

A obra Pele Silenciosa, Pele Sonora: A literatura indígena em destaque, da pesquisadora Janice Thiél, além de abordar a arte desde seu primórdio, trazendo conhecimento a respeito da produção, convida o leitor a um trabalho com sugestões de atividades visando ajudar o professor a encontrar caminhos para a leitura dos textos. Além de colaborar com questões relativas à literatura produzida nas Américas e no Brasil, ajudando o profissional a se embasar teoricamente acerca dos fundamentos dessa produção, a pesquisadora oferece propostas de atividades que podem ser trabalhadas em sala, como a autora mesmo defende:

Este livro pode ser usado, indistintamente, por professores de qualquer um dos níveis do Ensino Fundamental. As análises e reflexões apresentadas podem motivar leituras e promover debates; as atividades sugeridas podem ser adaptadas a diversos níveis escolares. (THIÉL, 2012, p. 13) 
A autora reconhece que o assunto é novo nas instituições de ensino e que está sendo mais fortalecido dentro das universidades com estudos que buscam teorizar e amparar a prática educativa. Alerta sobre a necessidade da temática nas escolas por favorecer a criticidade que se busca na formação educacional. Por meio dos estudos a respeito e com a literatura indígena, a autora defende que é possível transformar essa quase invisibilidade da arte na escola em um campo rico de troca de saberes.

Sendo assim, acredita-se na necessidade do preparo profissional para trabalhar a literatura indígena na escola. Os pares precisam buscar a compreensão do material que vai além de seu conjunto estético que o caracteriza como literatura e se aprofundar na história dessa produção e autoria. É preciso conhecer as histórias, lendas, mitos que se diversificam devido ao grande número de etnias, mas que se entrelaçam por um ponto comum: levar conhecimento do seu povo, sua cultura em busca da valorização e respeito. Acredita-se que com a leitura dessa obra, o profissional inicia sua compreensão em torno dessa literatura e pode iniciar trabalhos com obras disponíveis na escola.

A obra Contrapontos da literatura indígena contemporânea no Brasil de Graça Graúna, crítica literária, contribui para o conhecimento da literatura indígena no âmbito de sua criação. Apresenta sob um viés de discurso analítico as produções literárias no Brasil contemporâneo, marcado pela diversidade de culturas que a exemplo das culturas indígenas se utilizam da palavra escrita para "suplementar e subverter o discurso monocultural do cânone crítico literário" (Roland Valter, 2012, p. 13).

Ao trazer uma revisão da influência e da representação do índio na literatura brasileira escrita pelo não índio, discute a produção indígena como uma ferramenta de luta e resistência, buscando tratar as relações das obras de autoria indígena em relação a conceitos de identidade, auto história, alteridade com base em estudos culturais e defende:

Gerando sua própria teoria, a literatura dos povos indígenas no Brasil pede que se leiam as várias faces de sua transversalidade, a começar pela estreita relação que mantém com a literatura de tradição oral, com a história de outras nações excluídas (as nações africanas como exemplo), com a mescla cultural e outros aspectos fronteiriços que se manifestam na literatura estrangeira e, acentuadamente, no cenário da literatura nacional (Graúna, 2013, p. 19).

Trilhas literárias indígenas para a sala de aula de Sueli de Souza Cagnetti e Alcione Pauli é um instrumento que busca contribuir para a compreensão e trabalho do mediador, abordando a questão da literatura indígena na escola, partindo da dificuldade do processo de 
apropriação dessa leitura e da reflexão a respeito dessa produção. No prefácio da obra, Roni Wasiry Guará, escritor, professor e pesquisador, descendente da etnia Maraguá, declara:

Excursões a trilhas como essas nos dão argumentos necessários que conduzem a uma resposta convincente a quem quer reinventar, reolhar e viver a história em uma esfera mais clara, sabendo que em cada ato do conhecer há dois lados sempre! (apud CAGNETTI e PAULI, 2015, p.09)

As autoras reconhecem os esforços e investimentos na produção e divulgação de materiais que sintetizam a trajetória histórica das culturas indígenas brasileiras e a pluralidade das etnias. Entretanto, percebem a dificuldade e a carência de ferramentas que ajudem a direcionar a prática com a literatura indígena em sala de aula e buscando atender ao que pede a Lei 11.645/08 e apresentam um material que vai além de abordar temáticas indígenas, trilhando textos que marcam a não existência de uma uniformidade de etnia e cultura indígena que muito ainda se percebe nos discursos. A respeito disso, as autoras explicam:

Não existe uniformidade, definitivamente, mas a escola insistiu por muito tempo em padronizar tudo que por lá passa, e em especial a cultura indígena. As etnias são várias, há muitas peculiaridades entre elas e não regras fechadas, pois elas se abrem para o diálogo ou mesmo para o confronto (CAGNETTI e PAULI, 2015, p. 13 e 14).

Apropriando-se de textos diversos que tratam a cultura indígena com histórias que contam um mito sob vários pontos de vistas, identificando o ponto comum: a memória, que acentua o saber ancestral que estes povos valorizam e muito trabalham em sua literatura, as autoras levantam discussões em torno das várias etnias, suas semelhanças e diferenças e defendem que a leitura desses textos convida professores e alunos "a sentirem o cheiro das florestas, a presença do mágico, a força da união, a filosofia indígena" (CAGNETTI e PAULI, 2015, p. 57).

Defendem que o sentimento de coletividade conecta muitas obras de autoria indígena e que compõem material de grande relevância para a desconstrução de conceitos que precisam ser revistos pela mediação do professor.

Possibilitar a discussão dessas obras em sala de aula contribuirá significativamente para a ressignificação dos olhares sobre o conhecimento dos povos ancestrais e para o entendimento de quem são os indígenas, onde estão, que língua falam e onde vivem, pois as próprias obras contextualizam muitos desses dados (CAGNETTI e PAULI, 2005, p. 29). 
As pesquisadoras acreditam que a falta de disciplinas nas licenciaturas que abordem as temáticas indígenas e africanas colaboram para que falsas concepções continuem sendo reproduzidas. Ainda assim, reconhecem que, paulatinamente, esse quadro vem se modificando dentro dos meios acadêmicos, pela necessidade de estudos que envolvam teorias e práticas e intentam com essa obra, colaborar para essa mudança, convidando os profissionais a trilhar por novos caminhos.

\section{As fabulosas fábulas de Iauaretê de Kaká Werá Jecupé: uma proposta para o estudo da literatura indígena}

Escritor de origem Tapuia, Kaká Werá Jecupé parte de sua experiência com as sociedades indígena e não indígena e outros escritores e inicia um projeto de criação literária para contar a histórias dos povos indígenas. No convívio com outros povos, ouviu mitos e lendas da memória que fez com que ele trouxesse essas histórias, recontando-as na intenção de levar por meio da escrita o conhecimento e manutenção dos valores necessários para o convívio em sociedade. Incentivado pelo pai a aprender a ler e escrever, sob o argumento da necessidade futura de preservar a cultura, apropria-se das muitas histórias ouvidas e se utiliza da escrita para mantê-las. Em depoimento gravado durante o evento Mekukradjá - Círculo de Saberes de Escritores e Realizadores Indígenas, em setembro de 2016, em São Paulo/SP, afirma acreditar no "poder da oralidade, da história como algo capaz de promover a lapidação e expansão de uma consciência” (KAKÁ WERÁ, 2016).

O escritor indígena escreveu para o público adulto e infantil e entre eles As fabulosas fábulas de Iauaretê, onde a filha narra ao pai o que lembra das histórias contadas por ele, quando era mais nova. As fábulas narram as aventuras e desventuras de uma onça e, de maneira divertida, abordam o medo, a coragem, a morte, a dúvida, o amor, a paz, a oportunidade, os erros e acertos que vivenciamos em nossa existência.

Depois de tornar-se guerreiro Kamaiurá, a onça casou com Kamakuã, a bela, que gerou Iauaretê-mirim. A obra conta os melhores momentos de uma das mais divertidas lendas do ideário Guarani: as aventuras da onça Iauaretê e de seus filhos, Juruá e Iauaretê-mirim. As ilustrações foram feitas por Sawara, filha do autor, na época com 11 anos, quem o escritor afirma ter como leitora primária de suas obras até hoje e ainda no depoimento declara que:

Quando eu escrevo para minha filha, eu estou querendo escrever para futuras gerações para que elas não cometam as mesmas besteiras que eu cometi, os mesmos erros que minha geração cometeu e para que elas não caiam nos 
mesmos tipos de julgamentos que a minha geração caiu em relação aos erros dos outros (Kaká Werá Jecupé, 2016).

Assim como outros escritores indígenas, Kaká Werá busca levar conhecimento e reflexão com suas produções de maneira que sensibilize o outro para que seu olhar seja de respeito às diferenças e não de julgamentos. Preocupado em trazer para a contemporaneidade elementos da ancestralidade de seu povo, o autor apresenta na obra, como explica Jecupé (2007): “o jeito 'índio' de contar, o jeito fantástico que ele ouviu e aprendeu”. Dessa maneira, a tradição de contar histórias oralmente fica enriquecida pela escrita e os saberes adquiridos com a vivência e reinvenção da experiência ampliam a possibilidade de compreensão. Esse vínculo com a transmissão oral afirma o que Roland Walter defende: “A Literatura molda ideias, crenças e ideais históricos e éticos contribuindo para a constituição da episteme cultural coletiva" (GRAÚNA, 2013, p. 11)

Para iniciar o estudo da obra As fabulosas fábulas de Iauaretê, é importante realizar uma pesquisa acerca do autor, sua origem, seus trabalhos como escritor e projetos que buscam divulgar as culturas indígenas. Em entrevista referente ao projeto que envolve trabalhos de encenação da obra pelo Grupo Manuí, Kaká Werá defende que a “arte de contar histórias é a pedagogia que através do lúdico, [...] trazem histórias de superação, respeito, interatividade, integração à natureza e vão fazendo com que as pessoas internalizem determinados princípios”.

Uma das possiblidades para o trabalho com a obra com os alunos é trazer o conhecimento das fábulas de Esopo. Surgidas no oriente, as histórias traziam um ensinamento ao final da narrativa e apresentavam animais com características humanas como personagens. A finalidade dessa criação era ajudar na formação das crianças, ensinar a elas valores humanos. Por esse caráter educativo, são utilizadas na escola. Como explica Arruda (2010):

as fábulas poderão ser utilizadas como alternativa metodológica que permite esclarecer de forma agradável "uma verdade" a fim de ensinar virtudes aos alunos pois, desde a antiguidade, a moral implícita nas fábulas tem contribuído para o desenvolvimento da criança, além de este ser um recurso de entretenimento capaz de trabalhar a formação de valores dentro e fora da escola.

A partir dessa semelhança com as narrativas da obra de Kaká Werá, discutir o gênero em questão e envolver os alunos com as leituras, fortalecendo o senso crítico a partir dos ensinamentos que apresentam. A exemplo, a narrativa presente na obra $\mathrm{O}$ pajé e o ratinho, fábula que conta a respeito da insatisfação do ratinho com sua condição e pede ao pajé que o 
transforme em sapo, depois em onça, em seguida em gavião e finaliza sendo transformado no próprio pajé. A história nos ensina que devemos aceitar nossa essência e limitações, não sofrer com medo do futuro, pois esse sentimento já implica a derrota.

Na sequência, a contextualização da literatura indígena, da cultura da qual faz parte o autor, promovendo dessa forma o conhecimento da existência de outras culturas indígenas. Propor questões que reflitam as ações dos personagens a fim de trazer reflexões referentes à temática indígena e os ensinamentos presentes na narrativa:

1-Quem é o pajé numa aldeia?

2-Por que ele pode realizar as transformações?

3-Existe essa aldeia Kamaiurá das Águas Claras da Lagoa Morená?

4-Quais outras aldeias você já ouviu falar?

5-Por que o pajé não adverte o ratinho e faz todos os seus desejos?

6-O que podemos concluir das transformações do pajé?

Com estas possibilidades de questionamentos, podemos levar o aluno a refletir a respeito da educação indígena, as crenças, os costumes e também levá-lo a conhecer como se organiza a vida na aldeia e como se singularizam as diferentes culturas. Por fim, podemos, principalmente, ensiná-lo a respeitar as diferenças culturais e a individualidade de cada ser.

\section{CONSIDERAÇÕES FINAIS}

Um trabalho em sala de aula neste âmbito intercultural exige que o profissional entenda a peculiaridade da escrita indígena. Cagnetti e Pauli (2015) explicam que, sendo oriunda da oralidade, a linguagem dessa literatura se distancia do que estamos acostumados com as leituras de produção não indígena. É como acompanhar o pensamento do narrador, num fluxo que ora conta a história, ora a cultura, ora o autor e sua comunidade, situando o leitor geográfica, histórica e ou linguisticamente, fazendo com que o trabalho em sala considere essas pontuações e que estejam em pauta para o estudo da obra.

Dessa maneira, é preciso que o profissional se ampare teoricamente, buscando compreender melhor tudo que está relacionado à obra. Planejar estudos com textos de autoria indígena requer suporte teórico, para que a finalidade dessa literatura não contemple só a oferta de leituras diferenciadas, mas que sejam estudadas em seu completo contexto de produção.

Assim como a filosofia indígena acredita em uma teia que liga tudo e todos, os livros de literatura indígena estão entrelaçados em saberes esperando para serem descobertos, 
discutidos e apreciados em sala de aula. Que tal começar pelas Fabulosas fábulas de Iauaretê pela riqueza de sua construção, que resume toda uma prática milenar: o contar e recontar de histórias? Prática que é mantida pelos povos indígenas como forma de transmitir seus saberes e práticas, manter e buscar valorização de suas culturas que são materializadas pela escrita literária.

Que a pesquisa individual ou coletiva a respeito da produção literária indígena e seus autores seja um caminho para novos conhecimentos, novos conceitos e novas práticas. E a respeito do conhecimento necessário acerca dessa produção literária, a pesquisadora Janice Thiél (2012) reforça o objetivo dessa literatura, que é a busca do respeito e valorização do outro, pela expressão do outro e conclui, a respeito de sua obra, o desejo de que ajude professores e alunos a ampliar seus horizontes, se orientando e refletindo as textualidades indígenas com a negociação de sentidos.

Muitas obras de literatura indígena estão escritas para que essa negociação se efetive, que alcance as instituições de ensino e não passem despercebidas nas prateleiras da biblioteca, chegando à mão do professor que saberá exatamente o que precisa fazer e dará sua contribuição à arte e seu objetivo.

\section{REFERÊNCIAS}

ARRUDA, Soraia da Silva. O uso das fábulas no processo de ensino e aprendizagem no ensino fundamental. Disponível em:

<http://www.administradores.com.br/artigos/entretenimento/o-uso-das-fabulas-no-processode-ensino-e-aprendizagem-no-ensino-fundamental/46948/> Acesso em: 21 fev. 2019.

CAGNETTI, Sueli de Souza; PAULI, Alcione. Trilhas Literárias indígenas para a sala de aula. Belo Horizonte: Autêntica Editora, 2015.

DORRICO, Julie. DANNER, Leno Francisco. CORREIA, Heloisa Helena Siqueira. DANNER, Fernando. (Orgs). Literatura Indígena Contemporânea. Criação, Crítica e recepção. Porto Alegre: Editora FI, 2018.

GRAÚNA, Graça. Contrapontos da Literatura Indígena contemporânea no Brasil. Belo Horizonte: Mazza Edições. 2013.

JECUPÉ, Kaká Werá. As fabulosas fábulas de Iauaretê. São Paulo: Peirópolis. 2007.

THIÉL, Janice. Pele Silenciosa, Pele Sonora: A literatura Indígena em destaque. Belo Horizonte: Autêntica Editora, 2012. 
Kaka Wera- Encontros de Interrogação/2016. Disponível em:

<https://www.youtube.com/watch?v=6FuZQUlwxV4> . Acesso em: 24 jul. 2018.

As Fabulosas Fábulas de Iauarete. Disponível em:

<https://www.youtube.com/watch?v=DoY3LvvkUYY> Acesso em: 24 jul. 2018. 